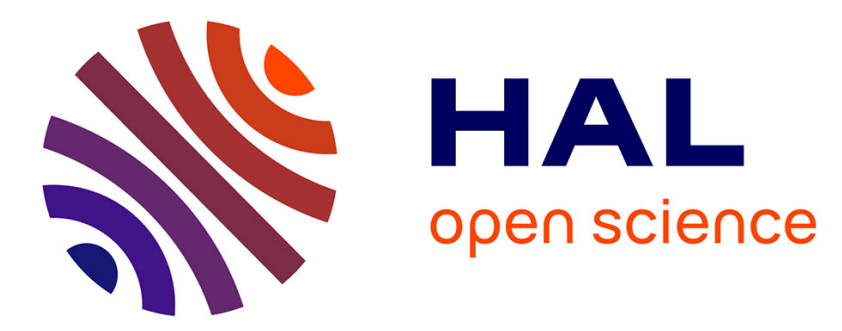

\title{
Spectroscopic Investigation of Nitric Acid Monohydrate
} Philipp Baloh, Hinrich Grothe, Karin Whitmore, Stewart F. Parker, Beatriz

Martín-Llorente, Rafael Escribano

\section{To cite this version:}

Philipp Baloh, Hinrich Grothe, Karin Whitmore, Stewart F. Parker, Beatriz Martín-Llorente, et al.. Spectroscopic Investigation of Nitric Acid Monohydrate. Molecular Physics, 2011, pp.1. 10.1080/00268976.2011.593571 . hal-00716636

\section{HAL Id: hal-00716636 https://hal.science/hal-00716636}

Submitted on 11 Jul 2012

HAL is a multi-disciplinary open access archive for the deposit and dissemination of scientific research documents, whether they are published or not. The documents may come from teaching and research institutions in France or abroad, or from public or private research centers.
L'archive ouverte pluridisciplinaire HAL, est destinée au dépôt et à la diffusion de documents scientifiques de niveau recherche, publiés ou non, émanant des établissements d'enseignement et de recherche français ou étrangers, des laboratoires publics ou privés. 


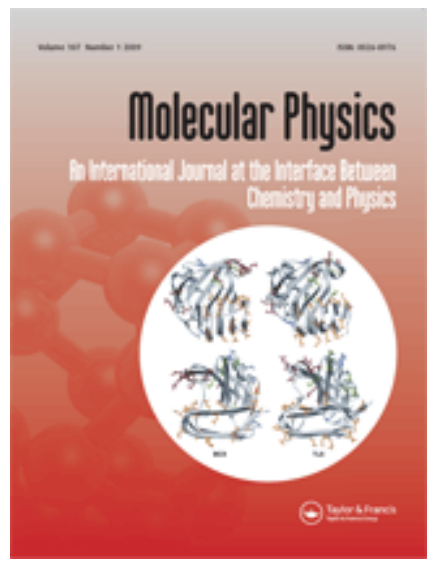

\section{Spectroscopic Investigation of Nitric Acid Monohydrate}

\begin{tabular}{|r|l|}
\hline Journal: & Molecular Physics \\
\hline Manuscript ID: & TMPH-2011-0090.R1 \\
\hline Manuscript Type: & Special Issue Paper - Dijon HRMS \\
\hline Date Submitted by the & 23-Mathor:2011 \\
\hline Complete List of Authors: & $\begin{array}{l}\text { Baloh, Philipp; Vienna University of Technology, Institute of } \\
\text { Materials Chemistry } \\
\text { Grothe, Hinrich; Vienna University of Technology, Institute of } \\
\text { Materials Chemistry } \\
\text { Whitmore, Karin; Vienna University of Technology, Universitaere } \\
\text { Service-Einrichtung fuer Transmissionselektronenmikroskopie } \\
\text { (USTEM) } \\
\text { Parker, Stewart; ISIS Facility, STFC Rutherford Appleton Laboratory } \\
\text { Martín-Llorente, Beatriz; IEM-CSIC, Instituto de Estructura de la } \\
\text { Materia } \\
\text { Escribano, Rafael; IEM-CSIC, Instituto de Estructura de la Materia }\end{array}$ \\
\hline Keywords: & \begin{tabular}{l} 
IR, Raman spectroscopy, Nitric acid monohydrate, INS \\
\hline
\end{tabular} \\
\hline
\end{tabular}


Philipp Baloh, ${ }^{a}$ Hinrich Grothe, ${ }^{* a}$ Karin Whitmore, ${ }^{b}$ Stewart F. Parker, ${ }^{c}$ Beatriz Martín Llorente, ${ }^{d}$ and Rafael Escribano ${ }_{r}^{d}$

${ }^{a}$ Vienna University of Technology, Institute of Materials Chemistry, Getreidemarkt 9/BC/165, 1060 Vienna, Austria. Fax: +43158801 165980; Tel: +431 58801165122 ;

Deleted: Lehargasse 2-4 E-mail: grothe@tuwien.ac.at

${ }^{b}$ Vienna University of Technology, Universitaere Service-Einrichtung fuer

Transmissionselektronenmikroskopie (USTEM), Wiedner Hauptstr. 8,1040 Vienna, Austria. Fax: +43 158801 13898; Tel: +43 158801 13728; E-mail:

ustem@ustem.tuwien.ac.at

${ }^{c}$ ISIS Facility, STFC Rutherford Appleton Laboratory, Chilton, Didcot, Oxon, OX11 oQX, United Kingdom. Fax: +44 1235 445720; Tel: +44 1235 446182; E-mail: stewart.parker@stfc.ac.uk

${ }^{d}$ Instituto de Estructura de la Materia, IEM-CSIC, Serrano 123, 28006, Madrid, Spain. Fax: +34 915855184; Tel: +34 915901609; E-mail: Rafael.escribano@csic.es

\begin{abstract}
Vibrational spectroscopy, X-ray diffraction, and electron microscopy have been applied to investigate the crystallization of concentrated amorphous nitric acid ( 0.5 $\leq \mathrm{x} \leq 0.95)$. Crystalline nitric acid monohydrate $\left(\mathrm{HNO}_{3} \cdot \mathrm{H}_{2} \mathrm{O}\right)$ is the major hydrate phase detected together with traces of metastable nitric acid dihydrate $\left(\mathrm{HNO}_{3} \cdot 2 \mathrm{H}_{2} \mathrm{O}\right)$ and pure crystalline nitric acid. Nitric acid tetratohydrate $\left(4 \mathrm{HNO}_{3} \cdot \mathrm{H}_{2} \mathrm{O}\right)$ was not achievable. The diffraction data show nitric acid monohydrate as a highly symmetrical structure, which bestows clearly laid out infrared, Raman and inelastic neutron scattering spectra. The low frequency region is still a matter of discussion since experiment and theory are not in accordance.

| The microscopic picture underlines the model character of nitric acid monohydrate, since the crystalline particles adopt a spherical shape, on various agglomeration stages, which minimizes the interference of scattering on the spectroscopic data.
\end{abstract} Deleted: (INS) 


\section{Introduction}

Nitric acid monohydrate (NAM) has been a subject of research for many different reasons over the years. The first publications concerning NAM were written in 1951 by Luzzati who solved the structure of solid NAM by single-crystal X-ray

diffraction (XRD). ${ }^{1}$ At that time, the interest was purely academic and the structures of several acids and their hydrates were solved in a similar way. In 1953 Bethell and Sheppard monitored solid and liquid NAM by IR-spectroscopy. ${ }^{2} 15$ years later, Janik et al. published the first inelastic neutron scattering (INS) experiments on solid NAM and other similar hydrates. ${ }^{3,4}$ They compared their results with existing IR and Raman data. A particular focus was on the low-frequency region. In 1974, Dawber carried out vapour pressure experiments with liquid $\mathrm{HNO}_{3}$ in the concentration region of NAM, in order to prove the stability of $\mathrm{H}_{3} \mathrm{O}^{+}$and $\mathrm{NO}_{3}{ }^{-}$ions. ${ }^{5}$ Delaplane $e t$ al. studied the hydrogen bonds of these NAM constituents using XRD and ab initio calculations. ${ }^{6}$ A subsequent paper of Janik et al. appeared in 1978, observing also the INS spectra of amorphous NAM and its crystallization changes. ${ }^{7}$ For a closer inspection of the amorphous state, in 1979 Herzog-Cance et al. analyzed the glass form of NAM as well as its changes during crystallization using fast Raman and wide-line NMR spectroscopy. ${ }^{8}$

In the early 1980s a decrease of the earth ozone layer was predicted and in 1985 a seasonal ozone depletion in the lower polar stratosphere was observed. ${ }^{9,10}$ In the following years much research was focused on polar stratospheric clouds (PSCs), which play a central role in heterogeneous stratospheric chemistry. Thus, the microphysical mechanisms of PSC formation became an important issue. Nitric acid hydrates (NAX) were found to be the major constituents of PSCs. ${ }^{11}$ These findings prompted the gathering of abundant information about the NAX species, including NAM. In this context, Hanson and Mauersberger presented their study of NAM, ${ }^{12}$ in which they also measured the vapour pressure over nitric acid mono- and trihydrate. Over the years several groups published infrared and Raman data of NAX comparing the features of the mono-, di- and trihydrate during different annealing procedures. ${ }^{13-19}$ This information was complemented by cluster experiments, kinetic measurements, $a b$ initio calculations, and XRD studies. ${ }^{20-26}$ Particularly for the purposes of heterogeneous chemistry, surface spectra of nitric acid hydrates were recorded using diffuse reflectance spectroscopy (DRIFTS), sum frequency 
generation (SFG), and grazing-angle reflection absorption infrared spectroscopy (RAIRS). ${ }^{22,27-32}$ These surface investigations showed molecular $\mathrm{HNO}_{3}$ to be present on the surface of NAM films. For comparison with field measurements the optical constants of nitric acid hydrates were determined. ${ }^{33}$

Today it is generally accepted that NAM has no real relevance in the micro-physics of PSCs because of the moderate concentration of nitric acid found at this altitude. However, the research on NAM carried on for another reason. Theoretical chemists discovered that NAM is a good model substance because it is simpler to calculate than any other hydrate and there already exists abundant information which can be used to test these calculations. During the last 15 years many investigations have been carried out to develop improved theoretical models. ${ }^{21,22,34-39}$ Only recently the $\mathrm{X}$-ray diffraction data have been re-investigated by Lebrun et al. ${ }^{40}$ improving the known structure and Walker et al. ${ }^{39}$ have determined the behaviour of NAM up to a pressure of $43 \mathrm{kbar}$ where three different structural phases have been identified. This paper aims to provide a more comprehensive picture of the structure and spectroscopic properties of NAM. To this end, we present new morphological information from environmental scanning electron microscopy (ESEM) and X-ray diffraction measurements, together with improved INS spectra. In addition, new IR and Raman data, with their spectroscopic analysis, are also given. The article is structured as follows. First, the experimental details of all techniques employed, are described. Next, the results attained by each technique are presented and discussed. The conclusions are outlined in a final section.

In the present paper, new spectroscopic data (FTIR, Raman and INS) and high level quantum chemical calculations are collected. These data are additionally correlated with morphological information from environmental scanning electron microscopy (ESEM).

\section{Experimental}

Specific sample preparation methods of NAM depended on the experimental analysis tool to be used. But all ways of preparation were based on concentrated solutions of $\mathrm{HNO}_{3}$ in $\mathrm{H}_{2} \mathrm{O}$. These solutions were quenched by different methods always with the aim to produce an amorphous sample, which was consequently crystallized in the course of an annealing program which included the following steps: 
(I) the amorphous sample was heated $\left(5 \mathrm{~K} \mathrm{~min}^{-1}\right)$ to a temperature above the glass transition point,

(II) the sample was kept at the constant temperature of interest until repeated short-term measurements revealed no further changes,

(III) the sample was cooled back to a temperature below the glass transition point $(125$

$\mathrm{K})$ and a long-term measurement was started.

Structural changes in the course of the subsequent thermal treatment were observed by X-ray diffraction, FTIR, Raman and INS spectroscopy. Additionally, environmental scanning electron microscopy was applied to a NAM sample to gain information about its morphology.

The set up for the XRD measurements was the same as that described in ref. 23 and 41 and therefore, it will only be discussed in brief here. It consists of three parts: an aerosol chamber, a sample compartment, and a high vacuum (HV) cryostat. To form the aerosol a Meinhardt ${ }^{\circledR}$ nebulizer (TR-50A1) was used to disperse the nitric acid solution. A Teflon slide separates the sample compartment from the high vacuum part with the colder surfaces of the cryostat. Thus, the sample may be kept under its own vapour pressure without any sample transfer to the cold cryostat surfaces. The sample support (gold plated aluminium) is mounted at the cold end of a helium closed-cycle cryostat (RGD 210 Leybold, Germany) which is located in the centre of a two cycle goniometer in Bragg-Brentano $\theta-\theta$-geometry (3000TT Seifert, Germany). Ni-filtered copper radiation $\left(\lambda_{1}\left(\mathrm{Cu}-\mathrm{K} \alpha_{1}\right): 1.54051 \AA ; \lambda_{2}\left(\mathrm{Cu}-\mathrm{K} \alpha_{2}\right): 1.54433 \AA\right)$ illuminates the sample through an aperture closed with a metalized Mylar foil of $40 \mu \mathrm{m}$ thickness. The scattered rays were collected by a scintillation counter.

The FTIR set-up was specially designed to protect its sensitive optical components in the course of quenching the aggressive mixtures. A detailed description of the apparatus can be found in the work of Tizek et al. ${ }^{41}$ The HV-cryostat chamber can be separated by a gate valve into a measurement chamber inside and a sampling compartment outside the spectrometer. An edge welded bellows with a jounce travel of $200 \mathrm{~mm}$ permits the sample support to be moved from one position to the other without any deterioration of the vacuum conditions. Spectra were recorded by coaddition of 10 scans at a resolution of $4 \mathrm{~cm}^{-1}$ with a Bruker $113 \mathrm{v}$ spectrometer (Karlsruhe/Germany). The IR-beam was focused on the gold plated sample support where the sample was analyzed in double transmission. Cooling was performed via dry air which was precooled to $80 \mathrm{~K}$ by heat exchange with liquid nitrogen. The 
coolant flowed into the sample carrier in the inner one of two concentric tubes and left the cryostat via the outer one. Thus a minimum temperature of less than $90 \mathrm{~K}$ is achieved. A temperature sensor (thermocouple) is located in an orifice directly below the carrier surface. Its accuracy could be determined by analyzing the vapor pressure of water and the $\alpha$ - $/ \beta$-transition of cyclohexane and it amounted to $\pm 1 \mathrm{~K}$. FTIR measurements require only a few seconds' time and spectra could be taken throughout the thermal treatment of the sample.

The preparation techniques for ESEM differ somewhat from the others. While in the case of XRD and FTIR an aerosol was deposited, for ESEM a droplet of approximately $4 \mu \mathrm{l}$ was quenched in a liquid nitrogen bath. To analyze the NAM sample the method of freeze fracturing proved to be very useful. A sample carrier with a hole was filled with the liquid sample thus producing a drop that projected above the hole. Then the sample carrier with the sample was quenched in liquid nitrogen and transferred to the preparation chamber of the ESEM. In the preparation chamber all parts were cooled with liquid nitrogen to a temperature of about 110 to $125 \mathrm{~K}$. The portion of the sample drop which lay above the sample carrier was broken away by a cold edge of a weld manipulator. The so-gained surface is clean and virgin and enables a very good analysis of the sample. Environmental scanning electron microscopy (ESEM) can be operated at higher pressures than traditional SEM. The NAM sample was observed under the pressure of an imaging gas $\left(\mathrm{N}_{2}\right)$ thus preventing the sample from evaporating. The measurements were done on a FEI Quanta 200 3D DBFIB at the University Service Centre for Transmission Electron Microscopy (USTEM) at the Vienna University of Technology. The annealing process was initiated in this case by stepwise heating the cryo-stage in the ESEM to the desired temperature. This procedure allows taking pictures while manipulating the temperature of the sample.

The production of samples for Raman spectroscopy was quite simple. For this purpose small glass capillaries (outer diameter $2 \mathrm{~mm}$, wall thickness $0.5 \mathrm{~mm}$, length $15 \mathrm{~mm}$ ) were filled with $4 \mu \mathrm{l}$ nitric acid solution $(50 \mathrm{~mol} \%)$. After the capillary was filled it was dipped into a liquid nitrogen bath where the sample froze to give an amorphous solid. This worked very well and was reproducible due to the very efficient heat exchange. The capillary containing the sample was then transferred into a cryostat where a temperature of $140 \mathrm{~K}$ was maintained by a cold nitrogen gas stream. The detailed description of this cryostat can be found elsewhere. ${ }^{42}$ The annealing could be done with a heating rate of approximately $5 \mathrm{~K} \mathrm{~min}^{-1}$. The spectra were recorded using a Dilor 
RTI30 spectrometer equipped with an argon ion laser $(514.5 \mathrm{~nm})$. The laser was guided through the double walled glass cryostat onto the sample capillary and the scattered light was collected perpendicular to the incident laser.

The INS measurements were carried out using $\operatorname{TOSCA}^{43}$ spectrometer at the ISIS Facility. ${ }^{44}$ TOSCA offers high resolution, $\sim 1.25 \% \Delta \mathrm{E} / \mathrm{E}$ between 16 and $4000 \mathrm{~cm}^{-1}$. The cryostat on TOSCA consists of a single stage closed cycle refrigerator (CCR, Leybold) that cools an outer radiation shield to $\sim 45 \mathrm{~K}$ and two dual stage $4 \mathrm{~K}$ CCRs (Sumitomo) that cool a central chimney, at the bottom of which the sample is mounted on the end of a special pole, a centrestick. (The neutron beam passes through the lower part of a

cryostat.) The sample is cooled by convection across a low pressure, 20 mbar, of helium exchange gas. To change sample, the chimney is filled with helium gas to atmospheric pressure, the centrestick withdrawn and exchanged for another with the next sample attached. The chimney is then evacuated to its operational pressure and the sample allowed to cool. The sample changeover can easily be accomplished in less than halfan-hour and the sample cools to base temperature $(\sim 12 \mathrm{~K})$ in about two hours.

For the sample preparation small droplets of about $4 \mu 1$ were quenched one after another directly in a liquid nitrogen bath. After that they were transferred onto the sample carrier still under liquid nitrogen. During this procedure the uttermost care was needed not to touch the sample with any parts that had not been cooled to liquid nitrogen temperature to avoid partial crystallization of the amorphous sample. The sample carrier was then transferred quickly out of the nitrogen bath into the cryostat of the TOSCA apparatus which had a temperature of approximately $20 \mathrm{~K}$. Then the analysis was started. A spectrum at $20 \mathrm{~K}$ was first recorded to ensure the amorphicity of the sample. In the annealing procedure the NAM sample was heated to $180 \mathrm{~K}$, cooled down, and finally the spectrum of the crystallized phase was recorded.

\section{Results}

\section{$\underline{\text { XRD data }}$}

Nitric acid monohydrate crystallizes in the orthorhombic space group $\mathrm{P} 2{ }_{1} \mathrm{cn}$ with cell parameters $a=6.317$ (3) $\AA$, b=8.723 (4) $\AA$ and $c=5.477 \AA$ (see Figure 1). ${ }^{40}$ The crystallographic data were used for calculating the powder diffractogram, shown at top of Fig. 2a as a bar diagram, in comparison with an experimental diffractogram of the 1:1 stoichiometry mixture. There is ample accordance, not only in signal positions but also in the relation of reflections' intensities (not evident in the bar 
diagram shown here). Disturbing influences like texture effects appear only to a very minor extent and do not affect the present analysis, which makes further refinement unnecessary.

\section{Figure 1}

The diffractograms in Figure 2a exhibit a clearly observable phase transition from amorphous to crystalline NAM starting at about $154 \mathrm{~K}$, which is $4 \mathrm{~K}$ above the glass transition point of the sample. ${ }^{45}$ In general, the diffractogram of an amorphous sample is unstructured and exhibits a broad intensity distribution about a wide angle range. In addition to the signal from the sample, there is also a signal from the cryostat itself, which results from the windows material and the sample carrier. During crystallization the respective reflections grow upon this background.

\section{FTIR data}

Whereas X-ray diffraction data supply the fundamental information of a phase transition, i.e. a change in the long-range order of the sample structure, vibrational spectroscopy can furnish information on the short-range order structural changes occurring during this phase transition. In Figure $\underline{2 b}$ there are three main frequency regions where changes become most obvious:

- Between 3300 and $3000 \mathrm{~cm}^{-1}$ the typical absorptions of the $\mathrm{OH}$-stretching vibrations of water disappear during crystallization.

- Conversely, strong bands at 2644 and $2226 \mathrm{~cm}^{-1}$ grow in the same process. These bands can be associated with $v_{1}$ and $v_{3}$ of $\mathrm{H}_{3} \mathrm{O}^{+}$whereas the emerging bands at 1663 $\mathrm{cm}^{-1}$ and $1116 \mathrm{~cm}^{-1}$ are assigned to $v_{4}$ and $v_{2}$ of the same cation, respectively. ${ }^{36}$ - A strong absorption at $1238 \mathrm{~cm}^{-1}$ can be assigned to the antisymmetric stretching band of $\mathrm{NO}_{3}{ }^{-}$. The symmetric stretching band $v_{1}\left(\mathrm{NO}_{3}{ }^{-}\right)$is infrared inactive. It is not observed at $1050 \mathrm{~cm}^{-1}$, but it does appear in the spectra of other nitric acid hydrates, sometimes as a split feature, revealing an asymmetric environment of the nitrate group.

Thus, the infrared spectrum provides evidence that in the amorphous sample (lowest trace in Fig. 2b), dissociation of the acid is not complete, and the neutral species coexist with a partial concentration of the ions. In addition, trace amounts of $\mathrm{N}_{2} \mathrm{O}_{4}$ have been trapped and detected (1742 and $1761 \mathrm{~cm}^{-1}$ ). This dimer is formed due to 
Higher $\mathrm{HNO}_{3}$ concentrations, with $0.5<\mathrm{x}<0.95$, have also been investigated. Pure nitric acid and NAM crystallize according to the respective stoichiometry, as expected from the phase diagram. $\frac{46.47}{}$ Traces of $\alpha$-NAD (phase I) appear due to the non-equilibrium conditions when crystallizing from the amorphous sample. ${ }^{23,48}$ With increasing concentration, the point of nitric acid crystallization drops below the of NAM. Figure 3 displays results for a nitric acid concentration of $54 \mathrm{~mol} \%$. The presence of crystalline nitric acid is confirmed by a XRD reflection at $26.3^{\circ}$ (Fig. 3, grey field). During annealing, the pure nitric acid starts to melt at the eutectic temperature of $208 \mathrm{~K}$ yielding NAM and the liquid phase (Fig. 3, $210 \mathrm{~K}$, top trace). Finally, it must be stated that no signs have been found for the existence of a tetratohydrate $4 \mathrm{HNO}_{3} \cdot \mathrm{H}_{2} \mathrm{O}(\mathrm{x}=0.83)$ which has been postulated based on differential scanning calorimetry, Raman spectroscopy, and vapour pressure measurements $\frac{49}{2}, 50$ In the test described here there are no other important changes besides the disappearance of the nitric acid signal (labeled NA) above the eutectic point at 208 $\mathrm{K}$. The monohydrate melts in accordance to the literature phase diagram at around $235 \mathrm{~K}$.

\section{Figure 3}

Undiluted nitric acid $(\mathrm{x} \sim 0.95)$ has been investigated as well but could not be frozen out fully amorphously: Several sharp and intense reflections appear on the 
unspecific background of the amorphous fraction (diffractogram not shown). The nitric acid ambient-pressure phase I has been identified unambiguously. ${ }_{-}{ }_{-}^{1}$ Neither from the diffractograms nor from the IR spectra can the ratio between amorphous and crystalline structures be derived. Obviously, pure nitric acid has a very low glass transition point. ${ }^{45}$ Crystallization of nitric acid already proceeds below $150 \mathrm{~K}$.

Therefore, measurements above $160 \mathrm{~K}$ rarely show any differences. Minor parts of the diffractogram show accordance with the diffraction pattern of NAM, the development of which indicates a slight crystalline impurity in the phase composition. The water of the NAM structure originates from the dissociation of $\mathrm{HNO}_{3}$ into $\mathrm{H}_{2} \mathrm{O}$ and $\mathrm{NO}_{2}$. Traces of $\mathrm{N}_{2} \mathrm{O}_{4}$ are detectable in the IR spectrum.

\section{INS data}

The spectrum labelled with $20 \mathrm{~K}$ in Fig. 4 is the first spectrum taken just after the sample was loaded into the cryostat, following the protocol described in the experimental part. At this stage, the sample is amorphous and has not been annealed yet. The spectrum largely resembles that of strongly disordered water found on metal oxides $^{52-55}$ and is assigned similarly: water translational and librational modes from 0 to $300 \mathrm{~cm}^{-1}$ and from 300 to $1100 \mathrm{~cm}^{-1}$, respectively, and the $\mathrm{H}-\mathrm{O}-\mathrm{H}$ scissors vibration at $\sim 1600 \mathrm{~cm}^{-1}$. The $\mathrm{O}-\mathrm{H}$ stretching modes are not seen on TOSCA because the momentum transfer, $Q(\AA)$, and the energy transfer, $E_{\mathrm{t}}\left(\mathrm{cm}^{-1}\right)$ are related by $Q^{2} \sim$ $E_{\mathrm{t}} / 16$ and thus for large energy transfer, $Q$ is also large and all the spectral intensity lies in the phonon wings (combinations of the internal modes and the external density of states), and as a result the high-frequency fundamentals are not observed. ${ }^{56}$ The only evidence for the presence of nitric acid is the peak at $\sim 1430$ $\mathrm{cm}^{-1}$ assigned to the $\mathrm{N}-\mathrm{O}-\mathrm{H}$ bend.

| As expected from the phase diagram and shown by XRD (Fig. a, trace (2)), the amorphous $50 \mathrm{~mol} \%$ nitric acid solution is fully converted into NAM, the only phase to crystallize, upon annealing to $180 \mathrm{~K}$. Immediately after tempering for 30 minutes, the sample was fast cooled to $20 \mathrm{~K}$. Since the amorphous/crystalline phase transition is irreversible, the measurement could be carried out at $20 \mathrm{~K}$ without interference. A spectrum with many intense narrow bands is thus recorded (Fig. 4, trace 2) and the difference to the spectrum of the amorphous phase (trace 1) is striking.

Our high resolution INS spectrum allows resolving broad structures as seen in the previous low resolution INS measurements by Janik et al. ${ }^{3}$. For example, the broad 
feature at $758 \mathrm{~cm}^{-1}$ observed by these authors is decomposed into at least six different bands in our work.

The uppermost calculated spectrum (trace 3) was generated from a previously reported $^{37}$ DFT calculation by the program ACLIMAX. ${ }^{57}$ Inspection of the eigenvectors shows that the INS spectrum is dominated by modes involving the

$\mathrm{H}_{3} \mathrm{O}^{+}$ion and can be divided into four regions: translational modes from 0 to 300 $\mathrm{cm}^{-1}$, librational modes from 600 to $900 \mathrm{~cm}^{-1}, \mathrm{H}-\mathrm{O}-\mathrm{H}$ bending modes from 900 to $1700 \mathrm{~cm}^{-1}$ and overtones and combinations at $>1700 \mathrm{~cm}^{-1}$. It can be seen that the $\mathrm{H}-$ Deleted: -
Deleted: -
Deleted: $\mathrm{O}-\mathrm{H}$ bending modes are reasonably well described, the librational modes are calculated somewhat higher than observed and the translational modes, shown in more detail in Fig. 5, are poorly represented by the calculation.

The reduced agreement between the observed and calculated INS spectra in the lowfrequency region arises from the choice of model employed. The energies and vibrational modes are calculated at the $\Gamma$-point (i.e. at wavevector $\kappa=0$ ) in the Brillouin zone, where infrared and Raman modes are allowed. In contrast, INS spectroscopy is sensitive to all wavevectors across the complete Brillouin zone. In cases where there is little or no dispersion in the modes there is usually good agreement between a $\Gamma$-point calculation and the observed spectra. ${ }^{56}$ That this is not the case for the present study but is strong evidence that there is significant dispersion in the modes. Hydrogen-bonded systems are well known to exhibit dispersion and the present example is a textbook case where such effects would need to be considered to accurately model the INS spectrum. Unfortunately, such a calculation is beyond our available resources.

\section{Figure 4}

The low-frequency region is enlarged in Fig. 5 where the calculated IR spectrum and the observed INS and Raman spectra (traces 1 to 3 respectively) are shown. The sample for the Raman spectrum was prepared in the way described above (ref. 19). All three spectra seem different at first glance, as corresponding to the diverse techniques used in each case. All vibrations where hydrogen is involved produce a strong signal in the INS spectrum, whereas in the Raman spectrum all vibrations which involve the movement of an oxygen atom are more intense due to the favoured change in polarizability, related to the higher electron density on oxygen 
atoms. The spectral features represented in Fig. 5 are listed in Table 1, with previous INS data and a tentative assignment of some modes. Some agreement can be found, especially in band positions, in the two regions alternatively covered by Raman observations and IR predictions. In the Raman and lower frequency part of the INS spectra, the two most prominent features seem correlated, with a small red shift in the Raman. In the higher frequency spectral region of the figure, the peak at $\sim 320$ $\mathrm{cm}^{-1}$ is present in both the INS and the predicted IR spectra, whereas the neutron scattering bands in the 200 to $250 \mathrm{~cm}^{-1}$ zone seem to be more spread in the calculated infrared trace. Atomic displacements per normal mode derived in the calculations indicate that most of these vibrations can be described as in-phase and out-of-phase twisting of the $\mathrm{NO}_{3}{ }^{-}$group and flattening of $\mathrm{H}_{3} \mathrm{O}^{+}$.

\section{Figure 5}

Table 2 presents a summary of previous and current assignments in the region between 600 and $1700 \mathrm{~cm}^{-1}$, covered by the INS measurements, as shown in Fig. 4. In general terms, there is a reasonably good agreement among all series of IR measurements and with the present INS spectra. The strongest INS bands correspond to vibrations of the oxonium ion: torsion, symmetric bending and asymmetric bending, at $\sim 750 \mathrm{~cm}^{-1}, 1130 \mathrm{~cm}^{-1}$ and $1670 \mathrm{~cm}^{-1}$ respectively, whereas the strongest IR bands are those assigned to the asymmetric stretching of the $\mathrm{NO}_{3}{ }^{-}$ion, at 1315 $\mathrm{cm}^{-1}$. 
Table 1. Low frequency vibrations (in $\mathrm{cm}^{-1}$ ) of NAM

\begin{tabular}{|c|c|c|c|c|}
\hline $\mathrm{INS}^{a}$ & $\mathrm{IR}^{b}$ & $\operatorname{Raman}^{c}$ & $\mathrm{INS}^{d}$ & Assignment $^{e}$ \\
\hline 59 & & 58 & & \\
\hline 70 & & 75 & & \\
\hline \multirow[t]{2}{*}{90} & & 86 & & \\
\hline & & 101 & & \\
\hline 124 & & 118 & 112 & \\
\hline 135 & & 129 & & \\
\hline 154 & & 143 & & \\
\hline 162 & & & 164 & \\
\hline 203 & 195 & & 206 & $\mathrm{Tz}$ \\
\hline \multicolumn{5}{|l|}{216} \\
\hline 238 & 234 & & & \\
\hline 249 & 268 & & 246 & Ty \\
\hline 300 & 304 & & & \\
\hline 318 & $320(\mathrm{sh})$ & & 321 & $\mathrm{Tx}+\mathrm{Tz}$ \\
\hline \multicolumn{5}{|l|}{387} \\
\hline 421 & & & & \\
\hline
\end{tabular}


Table 2: Vibrational spectroscopy data of NAM in the mid-IR region (in $\mathrm{cm}^{-1}$ )

\begin{tabular}{|c|c|c|c|c|c|c|c|}
\hline $\mathrm{INS}^{a}$ & $\mathrm{IR}^{b}$ & $\mathrm{IR}^{c}$ & $\mathrm{IR}^{d}$ & $\mathrm{IR}^{e}$ & $\operatorname{Raman}^{f}$ & $\mathrm{INS}^{g}$ & Assignment ${ }^{h}$ \\
\hline \multicolumn{8}{|l|}{603} \\
\hline \multirow[t]{2}{*}{673} & & 675 & 670 & 680 & & \multirow{11}{*}{758} & $\left(\mathrm{H}_{3} \mathrm{O}^{+}\right)$tors. \\
\hline & 702 & 700 & & 702 & & & $v_{\mathrm{L}}\left(\mathrm{H}_{3} \mathrm{O}^{+}\right)$ \\
\hline \multirow[t]{2}{*}{718} & 721 & 723 & 723 & 722 & & & $v_{4}\left(\mathrm{NO}_{3}^{-}\right) \delta_{\mathrm{as}}$ \\
\hline & 735 & 737 & 738 & 735 & & & $v_{4}\left(\mathrm{NO}_{3}\right)^{-} \delta_{\mathrm{as}}$ \\
\hline 750 & & & & & & & $\left(\mathrm{H}_{3} \mathrm{O}^{+}\right) \mathrm{Rz}+\mathrm{Ry}$ \\
\hline 770 & 780 & & & 775 & & & \\
\hline 798 & 814 & 815 & 816 & 813 & & & $v_{2}\left(\mathrm{NO}_{3}{ }^{-}\right) \delta_{\mathrm{s}}$ \\
\hline \multicolumn{7}{|l|}{877} & \\
\hline \multicolumn{7}{|l|}{926} & \\
\hline \multirow[t]{2}{*}{969} & & & & & & & calc. $\left(\mathrm{NO}_{3}^{-}\right) v_{1}$ \\
\hline & & & & & $\begin{array}{l}1044 \\
1055\end{array}$ & & \\
\hline 1103 & 1102 & & & & & & \\
\hline 1114 & & & & 1115 & & & $v_{2}\left(\mathrm{H}_{3} \mathrm{O}^{+}\right) \delta_{\mathrm{s}}$ \\
\hline 1131 & 1135 & 1135 & 1134 & & & & \\
\hline & 1279 & & & 1260 & & & $v_{3}\left(\mathrm{NO}_{3}{ }^{-}\right) v_{\mathrm{as}}$ \\
\hline 1314 & & & & 1316 & & & $v_{3}\left(\mathrm{NO}_{3}{ }^{-}\right) v_{\mathrm{as}}$ \\
\hline 1327 & & & & & & & \\
\hline 1402 & & 1386 & 1361 & & & & \\
\hline 1423 & & & & & & & \\
\hline 1437 & & & & & & & \\
\hline 1459 & & & & & & & \\
\hline 1669 & 1674 & 1680 & 1671 & 1671 & & & $v_{4}\left(\mathrm{H}_{3} \mathrm{O}^{+}\right) \delta_{\mathrm{as}}$ \\
\hline
\end{tabular}

${ }^{a)}$ INS data from this work, ${ }^{b)}$ IR data by Ritzhaupt and Devlin ${ }^{13},{ }^{c)}$ IR data by Savoie and Giguere ${ }^{56}{ }^{d)}$ IR data by Bethell and Sheppard ${ }^{2},{ }^{e)}$ IR data by Smith et.al. ${ }^{14},{ }^{f)}$ Raman data by Grothe et al. ${ }^{19}{ }^{g)}$ INS data by Janik et al. $\left.{ }^{4},{ }^{h}\right)$ the assignments are summarised from the different sources mentioned in the table.

\section{ESEM data}

During the laborious preparation of the sample outside and inside the microscope (see experimental section), the sample temperature was scrupulously kept below 125 $\mathrm{K}$, which is $30 \mathrm{~K}$ beneath the glass transition point of NAM. Thus, an amorphous state can be guaranteed when comparing with XRD and spectroscopic data. During the annealing the electron beam intensity was reduced in order to avoid damage to the sample or the initiation of an uncontrolled crystallization. Microscope pictures of high resolution were recorded only after re-cooling to $\mathrm{T} \leq 125 \mathrm{~K}$.

\section{Figure 6}


In Figure 6 the picture (a) shows an unstructured surface, which is in accordance with the assumption of a fully amorphous sample. In the pictures (b-d) the ongoing growth of the crystalline particles can be seen. After 10 minutes small spherical particles ( $200 \mathrm{~nm}$ in diameter) can be detected (Fig. 6b). Ten minutes later (Fig. 6c), the spheroids have increased their diameter by a factor of 5 (i.e. a growth rate of $80 \mathrm{~nm} \mathrm{~min}{ }^{-1}$ ), which corresponds to a volume gain of 125 in 10 minutes. This panel shows a mixture of particles at different stages in their growing process. After a further 10 minutes interval, the spheroids have merged forming a flocked carpet of NAM (Fig. 6d), in which individual spherical particles can still be detected on the surface of the structure.

\section{Conclusions}

NAM has been crystallized from various concentrated nitric acid solutions under extremely non-equilibrium conditions. Only one NAM phase (I) has been observed at low temperature and at ambient pressure, the same phase (I) achieved at $11 \mathrm{kbar}$, as stated in the literature, ${ }^{39}$ while the two further NAM phases (II, III) are only accessible at much higher pressure (42 and 43 kbar). Clearly, they cannot be generated by any non-equilibrium conditions at ambient pressure.

Spectroscopy and diffraction experiments indicate the presence of pure $\mathrm{HNO}_{3}$ in the amorphous samples, in accordance with previous SFG, DRIFTS, and RAIRS data

and theoretical studies. $\stackrel{60,61}{6}$ The reasons for that are, on one hand, demixing according to the phase diagram, and on the other hand, the elevated vapour pressure of $\mathrm{HNO}_{3}$ above the liquid. Molecular nitric acid is stabilized due to solvation but it tends to decompose into water and $\mathrm{NO}_{2}$, which has also been observed by spectroscopic means. The present INS data exhibit a much higher quality and better spectral resolution than the literature data, ${ }^{3,4}$ and have allowed to resolve some new band positions of water torsions and oxonium hindered rotations.

The ESEM pictures presented here provide unprecedented detail of the structure of NAM, which appears to be formed by spherical crystalline particles in various stages of agglomeration. This conclusion applies to samples grown on a gold support, whereas air-transported particles might be different. However, if we assume a 


\section{Acknowledgments}

This research project has been supported (in part) by the European Commission under the 7th Framework Programme through the Key Action: Strengthening the European Research Area, Research Infrastructures. Contract $n^{\circ}$ : CP-CSA_INFRA2008-1.1.1 Number 226507-NMI3. The STFC Rutherford Appleton Laboratory is thanked for access to neutron beam facilities. SFP is grateful for a lecture invitation by the Austrian Chemical Society (GÖCh). RE and BML acknowledge funding from the Spanish Ministry of Education, Project FIS2007-61686.

\section{References}

1 V. Luzzatit, Acta Cryst., 1951, 4, 239.

2 D. E. Bethell, N. Sheppard, Journal of Chemical Physics, 1953, 21, 1421.

$\underline{3}$ J. M. Janik, A. Jerzy, A. Bajorek, K. Parlinski, M. Sudnik-Hrynkiewicz, Physica, 1967, 35(4), 457.

4 J. A. Janik, A. Bajorek, J. M. Janik, I. Natkaniec, K. Parlinski, M. SudnikHrynkiewicz, Acta Physica Polonica, 1968, 33(3), 419.

5 J. G. Dawber, Journal of Inorganic and Nuclear Chemistry, 1975, 37(4), 1043.

6 R. G. Delaplane, I. Taesler, I. Olovsson, Acta Crystallographica Section B: Structural Crystallography and Crystal Chemistry, 1975, B31(5), 1486.

7 J. M. Janik, J. MA Janik, A. Bajorek, K. Parlinsk., M. Sudnikhr, Physica, 1967, 35(4), 457.

8 M. H. Herzog-Cance, J. Potier, A. Potier, J. M. Beny, B. Sombret, F. Wallart, Advances in Molecular Relaxation and Interaction Processes, 1979, 15(1),1.

9 M. J. Molina, F. S. Rowland, Nature, 1974, 249, 810.

10 R. S. Stolarski, A. J. Krueger, M. R. Schoeberl, R. D. McPeters, P. A. Newman, J. C. Alpert, Nature, 1986, 322, 808.

11 P. J. Crutzen, F. Arnold, Nature, 1986, 324, 651.

12 D. Hanson, K. Mauersberger, Geophysical Research Letters, 1988, 15(8), 855. 
13 G. Ritzhaupt, J. P. Devlin, Journal of Physical Chemistry, 1991, 95(1), 90.

14 R. H. Smith, M.T. Leu L. F. Keyser, Journal of Physical Chemistry, 1991, 95(15), 5924.

15 M. A. Tolbert, B. G. Koehler, A. M. Middlebrook, Spectrochimica Acta Part A, 1992, 48A(9), 1303.

16 T. L. Tso, M.-T. Leu, Analytical Sciences, 1996, 12(4), 615.

17 B. G. Koehler, International Journal of Chemical Kinetics, 2001, 33(5), 295.

18 K. D. Beyer, A. R. Hansen, Journal of Physical Chemistry A, 2002, 106(43), 10275

19 H. Grothe, C. E. Lund-Myhre, C, J, Nielsen, Journal of Physical Chemistry A, 2006, 110, 171.

20 N. Barton, B. Rowland, J. P. Devlin, Journal of Physical Chemistry, 1993, 97(22), 5848.

21 J. Koller, D. Hadzi, Journal of Molecular Structure, 1991, 48A(9), 1303.

$\underline{22}$ R. Escribano, M. Couceiro, P. C. Gomez, E. Carrasco, M.A. Moreno, V. J. Herrero, Journal of Physical Chemistry, 2003, 107(5), 651.

23 H. Tizek, E. Knoezinger, H. Grothe, Phys. Chem. Chem. Phys., 2002, 4(20), 5128.

24 R.G. Hynes, M.A. Fernandez, R.A. Cox, J. Geophys. Res., 2002, 107, 4797.

25 M. Staikova, D.J. Donaldson, Phys. Chem. Chem. Phys., 2001, 3, 1999.

26 P.R. McCurdy, W.P. Hess, S.S. Xantheas, J. Phys. Chem. A, 2002, 106, 7628.

27 S. Peil, S. Seisel, O. Schrems, Journal of Molecular Structure, 1995, 348, 449.

$\underline{28}$ H. Yang, B. J. Finlayson-Pitts, Journal of Physical Chemistry A, 2001, 105(10), 1890.

29 M. Sato, O. Setokuchi, K. M. T. Yamada, T. Ibusuki, Vibrational Spectroscopy, 2003, 31(2), 167.

30 H. Reinhardt, M. Fida, R. Zellner, Journal of Molecular Structure, 2003, 661-662, 567.

31 T.G. Koch, N.S. Homes, T.B. Roddis, J.R. Sodeau, J. Chem. Soc. Faraday Trans. 1996, 92, 4787.

$\underline{32}$ T.G. Koch, A.B. Horn, M.A. Chesters, M.R.S. McCoustra, J.R. Sodeau, J. Phys. Chem. 1995, 99, 8362.

| 33 A. M. Middlebrook, B. S. Berland, S. M. George, M. A. Tolbert, O. B. Toon, Journal of Geophysical Research, 1994, 99(D12), 25655.

34 R. D. Poshusta, D. C. Tseng, A. C. Hess, M. I. Maureen, Journal of Physical Chemistry, 1993, 97(28), 7295.

35 G. Toth, Journal of Physical Chemistry A, 1997, 101(47), 8871.

$\underline{36}$ D. Fernandez, V. Botella, V. J. Herrero, R. Escribano, Journal of Physical Chemistry $B, 2003, \mathbf{1 0 7}(\mathbf{3 8}), 10608$.

$\underline{37}$ D. Fernandez-Torre, R. Escribano, T. Archer, J. M. Pruneda, E. Artacho, Journal of Physical Chemistry A, 2004, 108(47), 10535.

38 D. Fernandez-Torre, R. Escribano, V.J. Herrero, B. Mate, M. A. Moreno, I. K. Ortega, Journal of Physical Chemistry B, 2005, 109(38), 18010.

39 M. Walker, C. A. Morrison, D. R. Allan, Physical Review B: Condensed Matter and Materials Physics, 2005, 72(22), 224106/1.

40 N. Lebrun, F. Mahe, J. Lamiot, M. Foulon, J. C. Petit, D. Prevost, Acta Crystallographica Section B: Structural Science, 2001, B57(1), 27.

$\underline{41}$ H. Tizek, E. Knoezinger, H. Grothe, PCCP, 2004, 6, 972.

42 F. A. Miller, B. M. Harney, Appl. Spectrosc. 1970, 24, 291.

43 D. Colognesi, M. Celli, F. Cilloco, R. J. Newport, S. F. Parker, V. Rossi-Albertini, F. Sacchetti, J. Tomkinson, M. Zoppi, Appl. Phys. A 2002, 74 [Suppl.], $\underline{\text { S64. }}$

44 http://www.isis.stfc.ac.uk/

Formatted: Bullets and Numbering 
45 K. Ji, Dissertation, L'Universite' de Paris VII, 1994.

46 S. U. Pickering, J. Chem. Soc., 1893, 63, 436.

47 N. LeBrun, F. Mahe, J. Lamiot, M. Foulon, J. C. Petit, Acta Crystallographica

Section C: Crystal Structure Communications, 2001, C57, 1129.

48 M. Walker, C. R. Pulham, C. A. Morrison, D. R. Allan, W. G. Marshall, Phys. Rev. B 2006, 73, 224110/1.

49 J. Potier, A. Potier, C. R. Acad. Sci. Paris 1956, 242, 1474.

| 50 M. Pham Thi, M. H. Herzog-Cance, A. Potier, J. Potier, J. Raman Spectrosc. 1981,

Formatted: Bullets and Numbering 11(2), 96.

51 D. R. Allan, W. G. Marshall, D. J. Fancis, I. D. H. Oswald, C. R. Pulham, C. Spanswick, Dalton Trans. 2010, 39, 3736.

52 W. Dmowski, T. Egami, K. E. Swider-Lyons, C. T. Love,; D. R. Rolison, J. Phys. Chem. B 2002, 106, 12677.

| 53 A. A. Levchenko, A. I. Kolesnikov, N. L. Ross, J. Boerio-Goates, B. F. Woodfield, G. Li, A. Navrotsky, J. Phys. Chem. A 2007, 111, 12584.

54 E. C. Spencer, A. A. Levchenko, N. L. Ross, A. I. Kolesnikov, J. Boerio-Goates, B. F. Woodfield, A. Navrotsky, G. Li, J. Phys. Chem. A 2009, 113, 2796.

55S. F. Parker, K. Refson, A.C. Hannon, E. Barney, S.J. Robertson, P. Albers, J. Phys. Chem. C 2010, 114, 14164.

56 P. C. H. Mitchell, S. F. Parker, A. J. Ramirez-Cuesta, J. Tomkinson, Vibrational spectroscopy with neutrons, with applications in chemistry, biology, materials science and catalysis, World Scientific: Singapore, 2005.

57 A. J. Ramirez-Cuesta, Comp. Phys. Comm. 2004, 157, 226.

58 R. Escribano, D. Fernández-Torre, V. J. Herrero, B. Martín-Llorente, B. Maté, I. K. Ortega, H. Grothe, Vibr. Spectr. 2007, 43, 254.

59 R.Savoie, P. A. Giguère, J. Chem. Phys., 1964, 41(9), 2698.

60 M. Hsinjui Kuo, A. David, N. Kamelamela, M. White, M. J. Shultz, J. Phys. Chem $C, 2007,111,8827$.

61 R. Bianco, S. Wang, J. T. Hynes, J. Phys. Chem. A, 2008, 112, 9467.

62 H. Grothe, H. Tizek, I. Ortega, Faraday Discussion, 2008, 137, 223. 


\section{Captions to figures:}

Fig.1: Projection of the crystal structure of NAM on the [001]-plane. This structure was calculated by refinement of the observed X-ray diffraction result. NAM consists | of separated and corrugated two-dimensional layers. ${ }^{40}$

Fig.2 a) (1) $\mathrm{X}$-ray diffractogram of an amorphous sample with $\mathrm{x}=0.5$ at $\mathrm{T} \leq 125 \mathrm{~K}$.

(2) $\underline{X}$-ray diffractogram of the same sample after annealing to $180 \mathrm{~K}$. The bar graph at top shows calculated reflections of NAM. SC indicates reflections of the sample carrier and the window.

Fig.2 b) (1) FTIR-spectrum of amorphous NAM at $125 \mathrm{~K}$. (2) Spectra of the same sample after crystallization at $180 \mathrm{~K}$, and (3) annealed at $200 \mathrm{~K}$, respectively.

Fig.3: X-ray diffractogram of 54 mol\% nitric acid at $180 \mathrm{~K}, 200 \mathrm{~K}$ and $210 \mathrm{~K}$. A reflection at $25.5^{\circ}$ indicates pure nitric acid and is shaded in grey (and labelled NA). It disappears above the eutectic temperature. A reflection at $15.9^{\circ}$ is an impurity of $\alpha$ NAD and is marked with " $D$ ".

Fig.4: INS spectra of NAM evolving from an amorphous phase of $50 \mathrm{~mol} \%$ nitric acid through annealing. The spectrum (1) shows the amorphous nitric acid ice mixture at 20 $\mathrm{K}$ as deposited before annealing. The spectrum (2) is taken after annealing to $180 \mathrm{~K}$. Spectrum (3) is a calculated spectrum for NAM.

Fig.5: Comparison of the low frequency range spectra of NAM by Raman (3) and INS (2), both experimental, and IR, calculated (1).

Fig. 6: ESEM pictures of NAM: (a) amorphous sample at $\mathrm{T} \leq 125 \mathrm{~K}$, (b) crystalline sample at $\mathrm{T}=180 \mathrm{~K}$, after $10 \mathrm{~min}$ annealing time, (c) same sample and same conditions but after $20 \mathrm{~min}$ annealing time, $(\mathrm{d})$ as before but after $30 \mathrm{~min}$ annealing time. 
Table 1. Low frequency vibrations $\left(\right.$ in $\mathrm{cm}^{-1}$ ) of NAM

\begin{tabular}{lllll}
\hline $\mathrm{INS}^{\mathrm{a}}$ & $\mathrm{IR}^{\mathrm{b}}$ & $\operatorname{Raman}^{\mathrm{c}}$ & $\mathrm{INS}^{\mathrm{d}}$ & Assignment $^{\mathrm{e}}$ \\
\hline 59 & & 58 & & \\
70 & & 75 & & \\
90 & & 86 & & \\
& & 101 & & \\
124 & & 118 & 112 & \\
135 & & 129 & & \\
154 & & 143 & & \\
162 & & & 164 & \\
203 & 195 & & 206 & $\mathrm{Tz}$ \\
216 & & & & \\
238 & 234 & & 246 & $\mathrm{Ty}$ \\
249 & 268 & & & \\
300 & 304 & & 321 & $\mathrm{Tx}+\mathrm{Tz}$ \\
318 & $320(\mathrm{sh})$ & & & \\
387 & & & & \\
421 & & & & \\
\hline
\end{tabular}

${ }^{a}$ INS data from this work, ${ }^{b}$ IR calculations by Escribano et al. ${ }^{55},{ }^{c}$ Raman data by Grothe et al. ${ }^{19},{ }^{d}$ INS data from Janik et al. ${ }^{4},{ }^{e}$ assignments by Janik et al. ${ }^{4}$ 
Table 2: Vibrational spectroscopy data of NAM in the mid-IR region (in $\mathrm{cm}^{-1}$ )

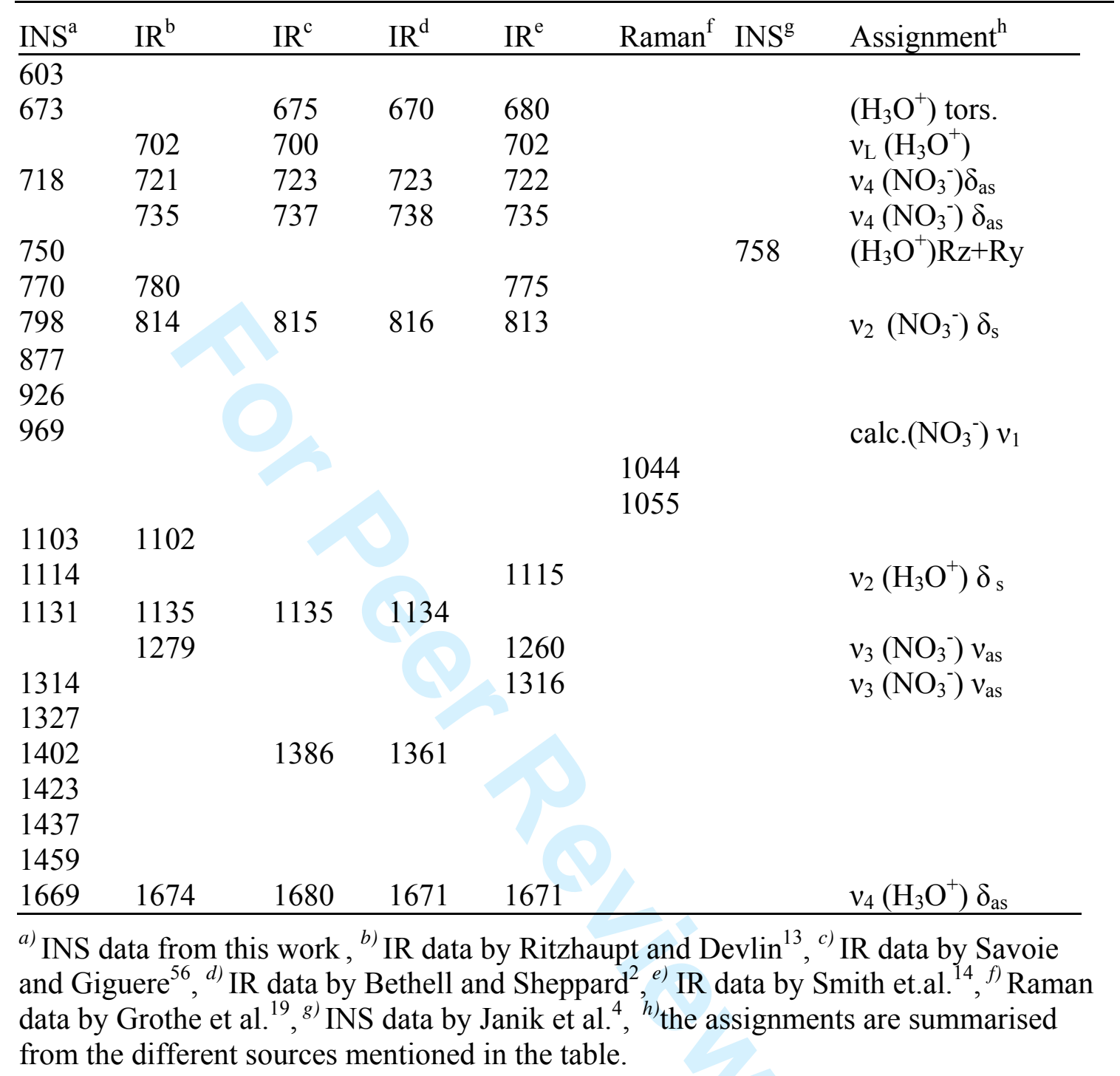




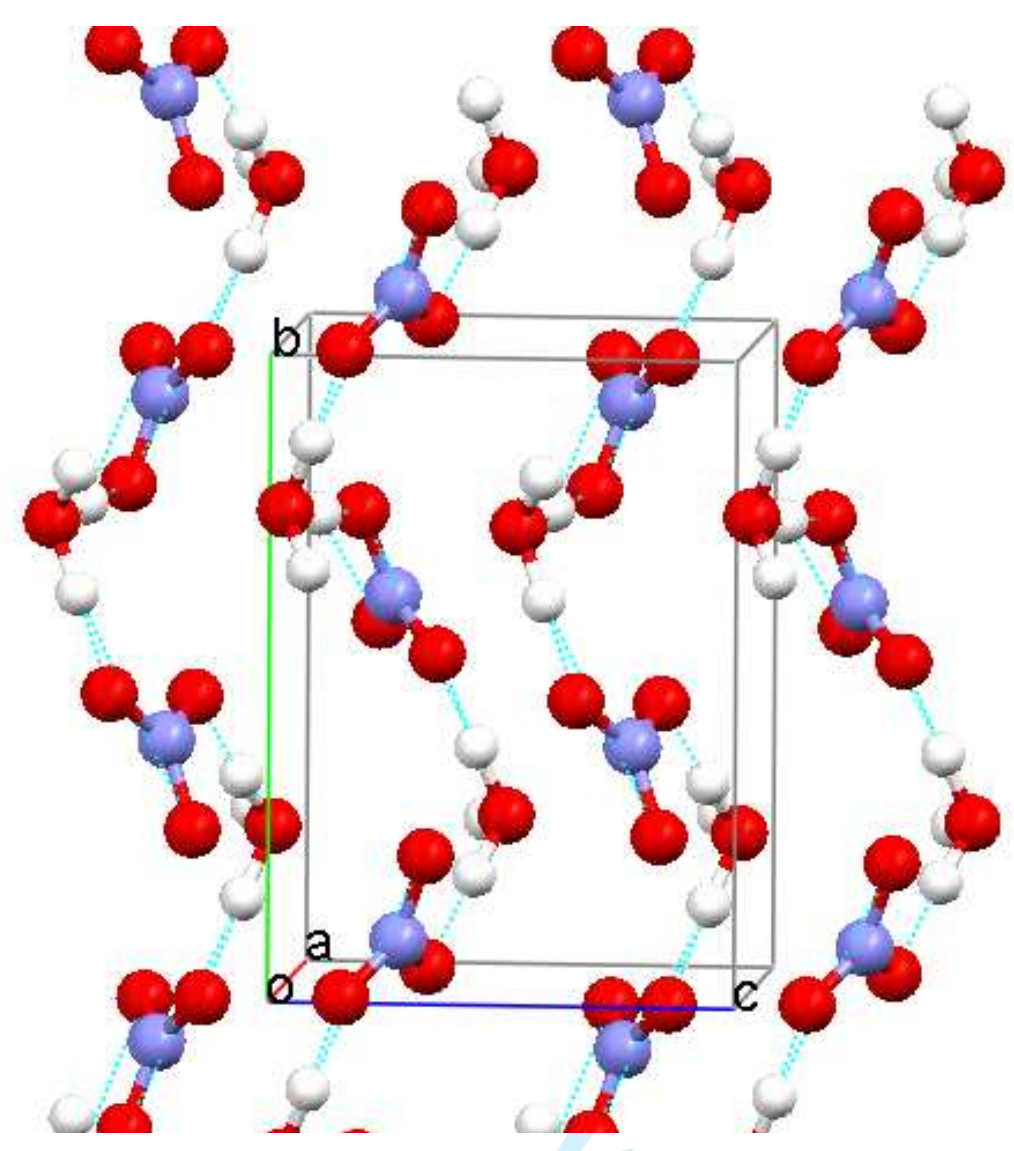

Figure 1 
a)

(2)

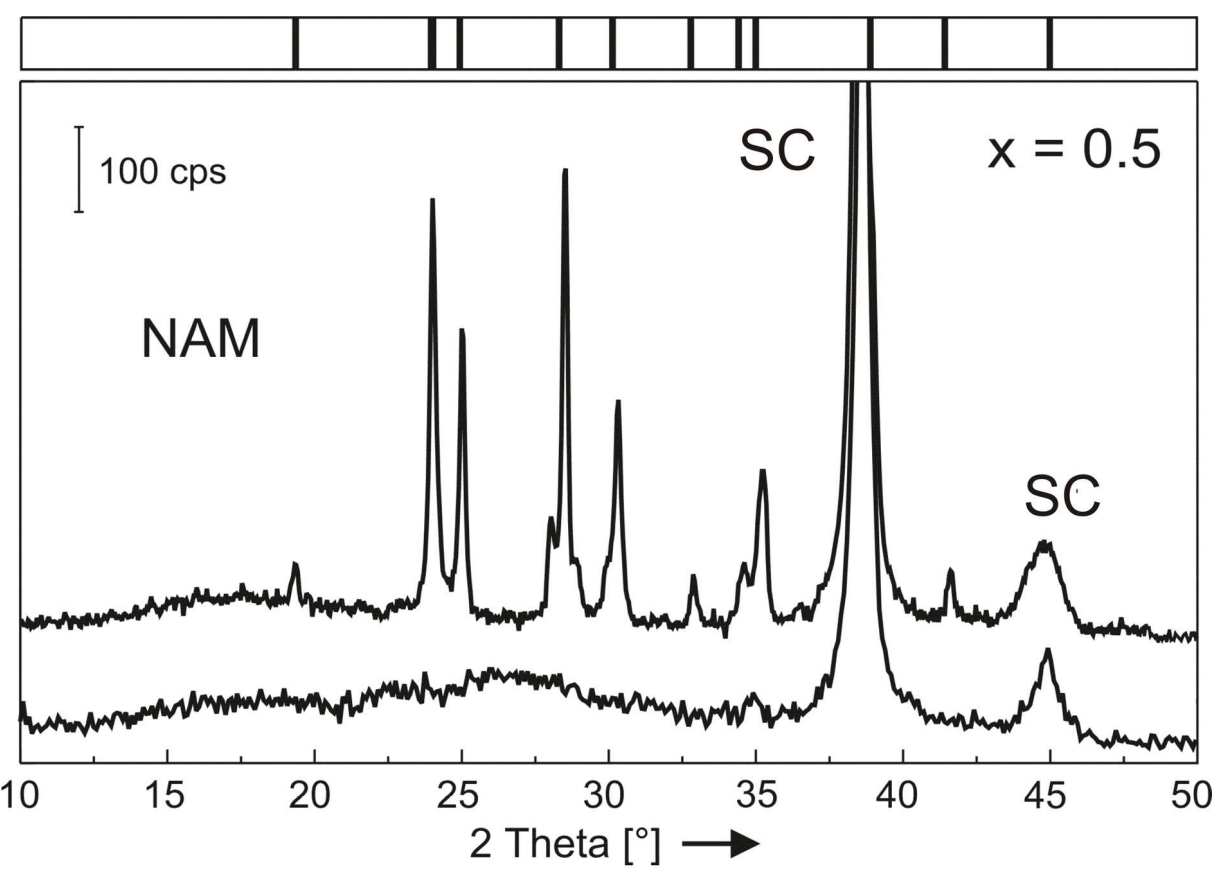

b)

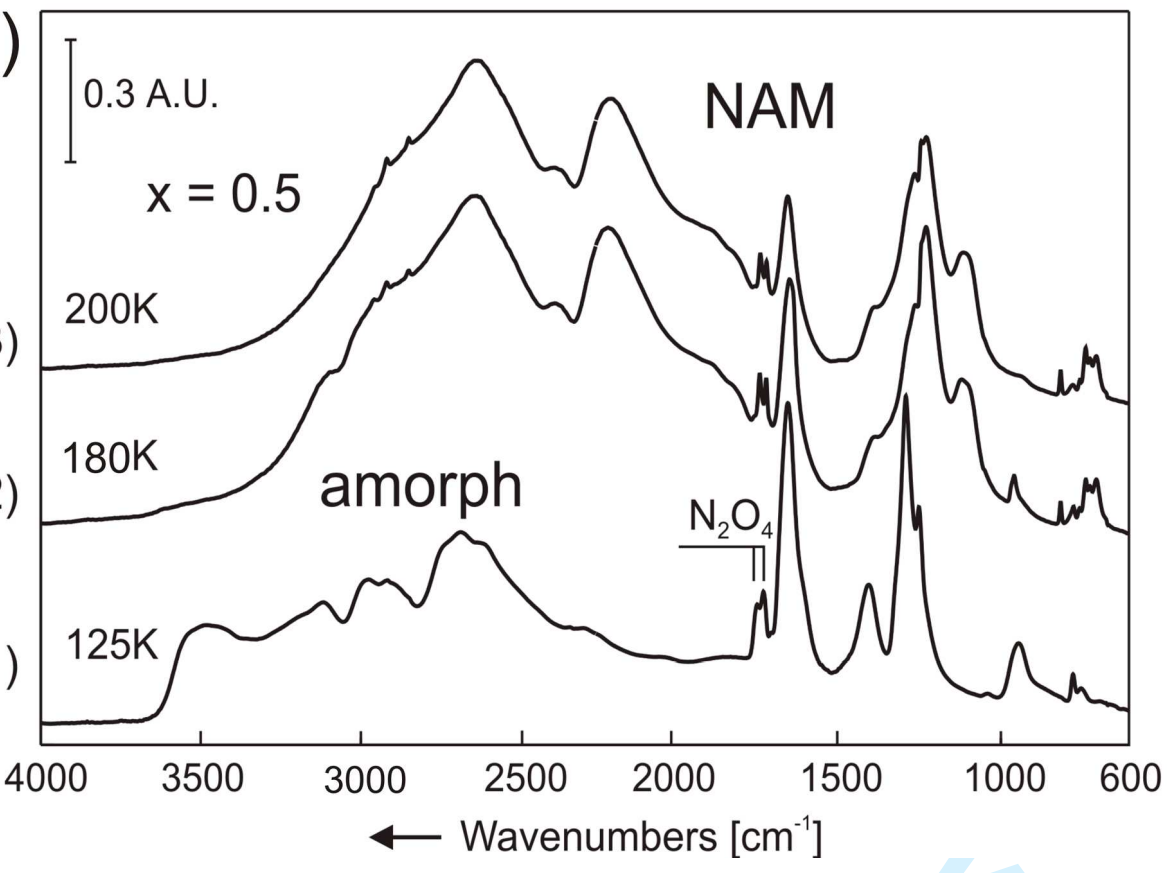

Figure 2 


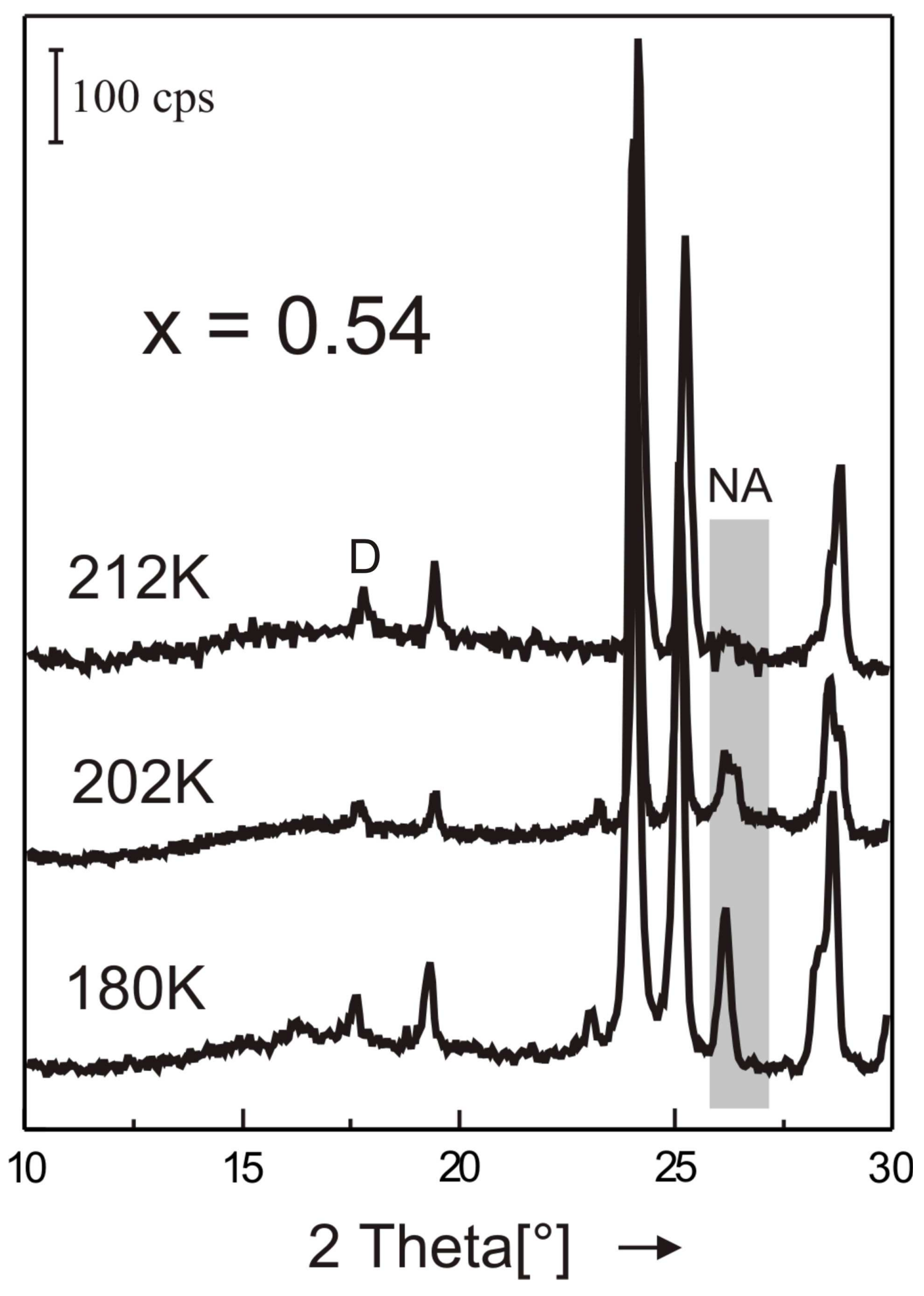

Figure 3 


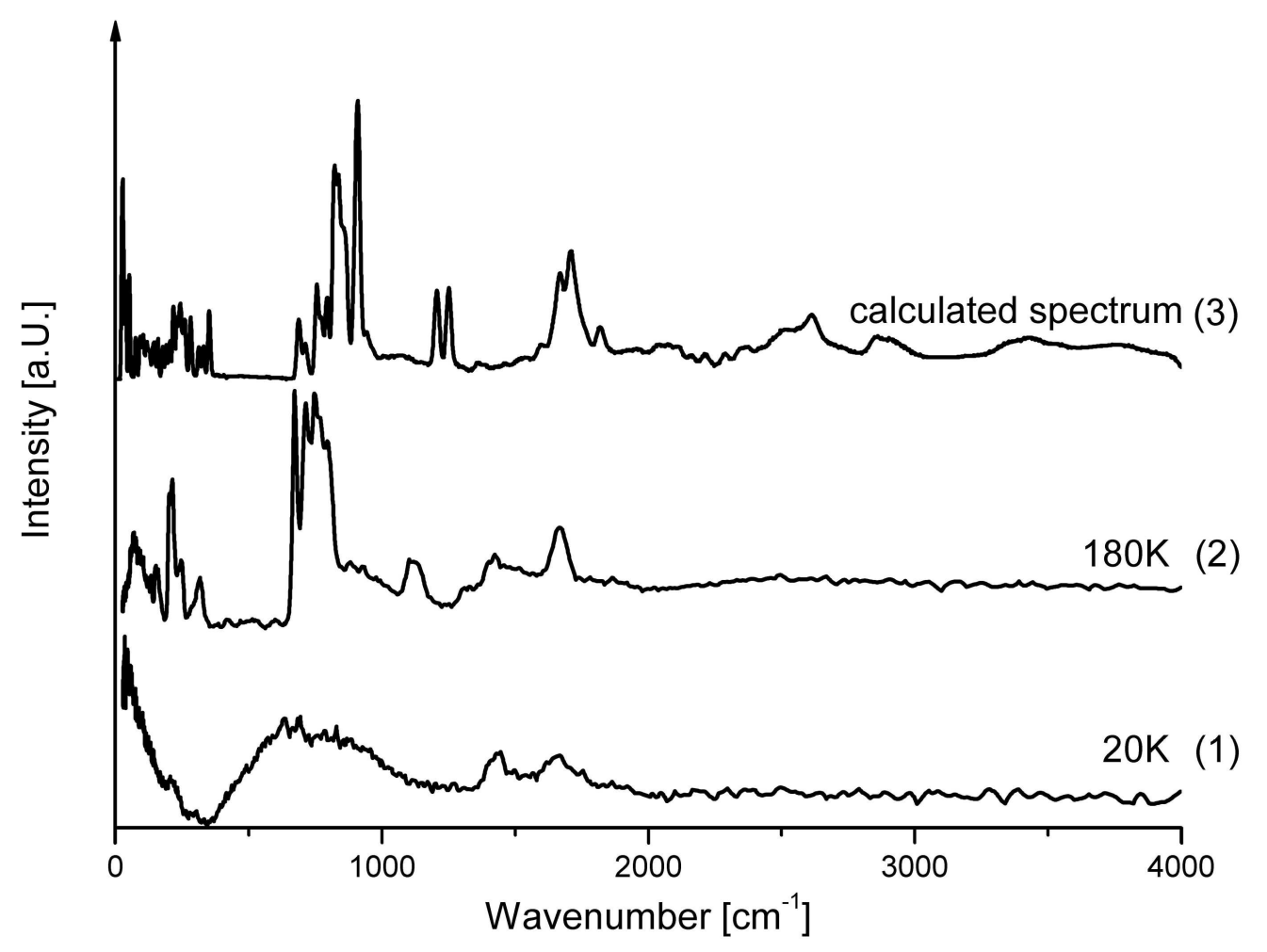

Figure 4 


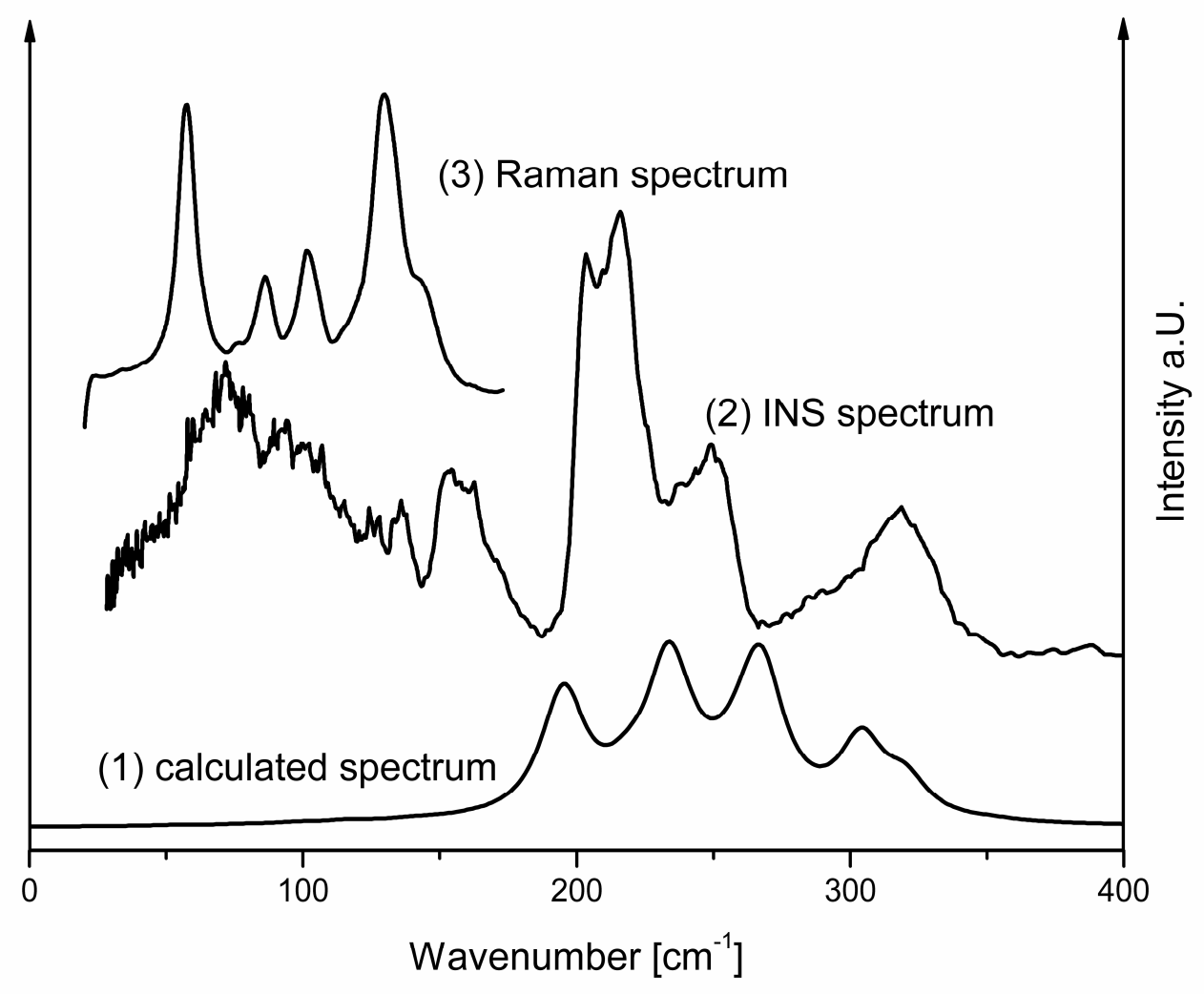

Figure 5 


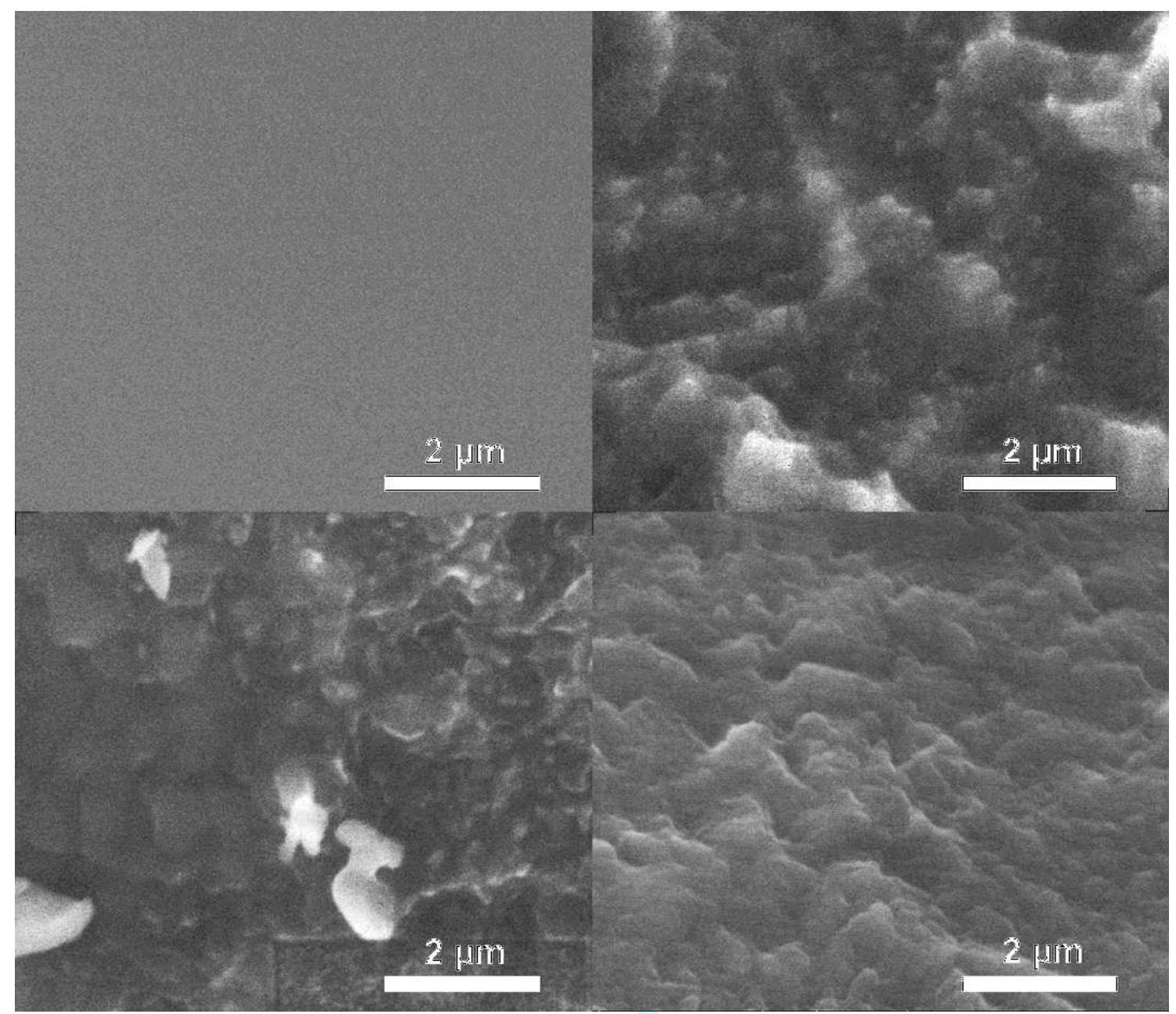

Figure 6 